OPEN ACCESS

Edited by:

Chris Elsden

University of Edinburgh,

United Kingdom

Reviewed by:

Joshua Hallwright,

Oxfam, United Kingdom

Raluca Bunduchi,

University of Edinburgh,

United Kingdom

${ }^{*}$ Correspondence:

Aiste Rugeviciute

aiste.rugeviciute@hec.edu

Specialty section:

This article was submitted to

Blockchain for Good,

a section of the journal

Frontiers in Blockchain

Received: 20 April 2019 Accepted: 30 September 2019

Published: 22 October 2019

Citation:

Rugeviciute $A$ and Mehrpouya $A$ (2019) Blockchain, a Panacea for Development Accountability? A Study of the Barriers and Enablers for

Blockchain's Adoption by Development Aid Organizations. Front. Blockchain 2:15

doi: 10.3389/fbloc.2019.00015

\section{Blockchain, a Panacea for Development Accountability? A Study of the Barriers and Enablers for Blockchain's Adoption by Development Aid Organizations}

\author{
Aiste Rugeviciute $^{1 *}$ and Afshin Mehrpouya ${ }^{2}$ \\ ${ }^{1}$ Technologies and Sustainability, The SASI Co., Paris, France, ${ }^{2}$ Accounting and Management Control Department, HEC \\ Paris, Jouy-en-Josas, France
}

In recent years, the term "blockchain" has been sprinkled widely and the hype around it attracts billions in investments. The promises that this technology can be a solution to many of society's present problems have drawn attention from all sectors, including development aid. The historical recognition of potential and actual corruption resulting from development aid sparked a rise in demands for more transparency and accountability in this sector. So far, there have been reflections in different academic disciplines about the potentials of Blockchain in this area. However, little empirical investigation has been conducted to understand the technological and institutional enablers and barriers for its adoption in the development aid sector. This study aims to take initial steps toward such understanding with a focus on the potential role for Blockchain Technology in financial aid flows through an analysis of the donors' perspectives. Our research is based on diverse qualitative material. It relies on reports and discussion papers produced by donor organizations and on case studies of two start-ups focused on introducing Blockchain into development aid management. Besides a body of archival qualitative material, we conducted interviews with different actors in the development financing field. Based on an inductive qualitative methodology, we grouped findings into three categories of barriers and enablers: discursive, technological, and institutional. Our study shows that discourses about Blockchain Technology vary a lot and there is a lack of common framing of its definition, attributes, and insufficient engagement around these concerns between different actors. Overall, the ability to increase the visibility of cash flows and a potential to reduce administration costs were perceived to be the most useful features, combined with the desire/need expressed by some donors to be at the forefront of technological developments. Lack of understanding about this technology and fear of its complexity and related security challenges were the most cited technological obstacles. Lack of institutional structures for rule making and for enabling field-level exchanges and knowledge production around Blockchain-based projects is currently the most prominent challenge to its diffusion and wider adoption.

Keywords: Blockchain, development aid, financial aid flows, barriers and enablers, donors' perception 


\section{INTRODUCTION}

With a shift from small "everybody knows everyone" communities to alienated big societies there is an on-going question of trust. How can people trust big bureaucratic bodies which claim to serve the public interest? How can trust be constructed at a distance? Blockchain Technology has attracted a lot of attention from different sectors by promising to increase the corroded trust in public institutions (The Economist, 2015; Ølnes et al., 2017).

The year 2017 could be considered as the peak of hype about this technology as visible in the explosion of cryptocurrency. The world saw more than $\$ 6$ billion funds raised in Initial Coin Offerings (ICOs) which raise money for a new cryptocurrency venture. However, according to Satis Group, an ICO advisory firm, as many as $81 \%$ of these ICOs were scams (Dowlat, 2018). In parallel to such pervasive opportunistic use of this technology, Blockchain is being slowly adopted by governments, civil society and inside firms as an enabler for decentralization, transparency and decreased transaction cost by cutting intermediaries (Corporate Tracker, 2018; Lyons et al., 2018b; Orcutt, 2018).

In this paper we look at the potentials of Blockchain Technology (BT) to become a tool to address trust-related issues in the development aid sector. The focus of this research is the development aid flows which often include many stakeholders and have complex underlying politics and procedures. A lot of existing research around Blockchain Technology speculates that it could be the answer to the need to improve transparency and accountability in the development aid sector by addressing issues such as lack of shared data between donors, duplication of donor efforts and lack of transparency in humanitarian aid flows (Davies, 2015; Swan, 2015; Galen et al., 2017; Hernandez, 2017; Pisa and Juden, 2017; Zambrano, 2017). However, little empirical research has been conducted to understand how this new technology could fit in the institutional and technological context of this sector. This study aims to contribute to this understanding by analyzing the barriers and enablers for the adoption of Blockchain Technology based on interviews and other qualitative material sourced from different actors in the world of development aid.

We have analyzed donor governments' and multilateral institutions' reports, websites and research articles around Blockchain Technology. In addition, we have carried five in-depth interviews with different actors involved in the development aid transparency debates, ranging from donors themselves to NGOs and technological service providers.

We have grouped the results into three categories: the discursive, the technological and the institutional enablers and barriers. The first category involves an analysis of the field-level discursive structures related to Blockchain Technology, that is: the diversity of views about Blockchain Technology, its benefits and the perceived obstacles to its adoptions in the development aid field. The second category covers the technological properties of Blockchain Technology which could act as enablers or, on the contrary, as barriers for the adoption of this technology. Finally, the last category includes the observations about regulations, standards, norms for BT in the development aid sector.
Based on our analysis, we suggest that one of the biggest barriers to wider adoption, is the existence of different discourses about this technology and its potential roles in development and competing articulations of problems and solutions. Furthermore, initiatives around Blockchain are highly fragmented with little exchange/engagement among them. We argue that there is a need to establish governance organizations that would provide platforms for debate and knowledge exchange, and for moving toward a common framing of the definitions, norms and standards essential to wider adoption of Blockchain Technology.

\section{DEVELOPMENT AID FLOWS}

In 2017 development aid flows by the OECD countries accounted for over 415 billion US dollars (OECD, 2019). Large sums of funds can make a big difference however they equally attract bigger potential problems: corruption, lack of transparency resulting in their inefficient distribution and even the smallest mistakes ending up in huge financial losses. UNICEF, for example, argues that since $30 \%$ of development aid fails to reach its destination, "just a 3\% improvement in its delivery would free up billions" (Blockchain Team, 2018, p. 12). Furthermore, the development sector has become an increasingly complex field leading to intensifying problems of traceability and accountability.

Each development agency usually supports a vast number of development activities at the same time in a variety of partner countries. There are also diverse funding mechanisms available. For example, humanitarian aid can be managed by the ministry of foreign affairs or a special humanitarian department in some countries, while others might choose to locate their humanitarian department within a separate development agency (OECD, 2005).

In addition to aid being distributed by single countries it can also be channeled as multilateral assistance through a number of established channels/organizations: multilateral development banks such as the World Bank or the Asian Development Bank, United Nations Agencies such as WFP, or the European Union through its European Development Fund (OECD, 2005). Figure 1 provides a broad overview of the actors involved in the distribution of development aid.

The complexity of development aid flows inevitably leads to operational and accountability issues (OECD, 2005, 2014). Lack of visibility around who is doing what ends up in a duplication of aid while leaving some other regions or issues underfinanced. Coordination challenges are also prevalent within the development agencies, especially with the thousands of staff located all over the world. Corrupt officials at times use the lack of transparency to their advantage and a considerable amount of Western aid never reaches the intended beneficiaries. The complexity and the large number of transactions between different parties inevitably lead to high transaction and operational costs. Finally, the beneficiary governments frequently lack a good overview where this aid is going and therefore struggle planning their future budget, prioritizing issues and projects. As a result, different constituencies have urged for more transparency and a 


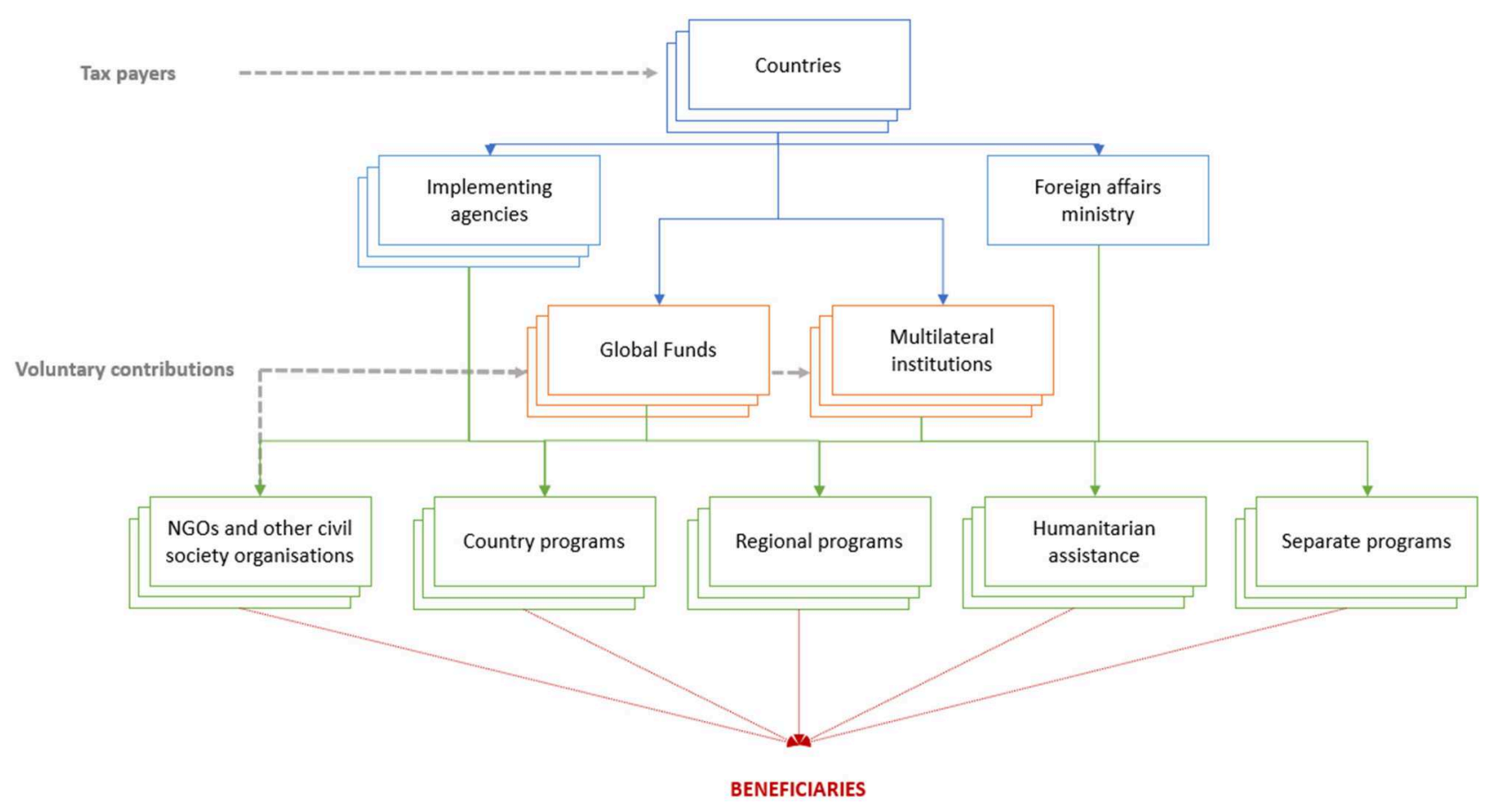

FIGURE 1 | Development aid flows.

better information sharing about aid to improve co-ordination, co-operation and accountability across the donor community (OECD, 2006, 2014; Publish What You Fund, 2010; High-Level Panel on Humanitarian Financing, 2016).

The common belief in the sector is that the pillars of accountability and transparency should go hand in hand and complement each other. The first one is evidence of impact reached and a justification of the actions taken, which can be done in a lengthy manner and can be presented either in quantitative or qualitative forms. The second one, on the other hand, is about making the information understandable and accessible for the stakeholders.

The perception that transparency and accountability are means to improve efficiency and effectiveness of aid delivery has been articulated in different initiatives. Paris Declaration on Aid Effectiveness, endorsed in 2005, by more than 100 donors and developing countries and multilateral agencies, reflects the recognition of the actors, involved in these development aid flows, of the need for "far-reaching and monitorable actions to reform the ways we deliver and manage aid" (OECD, 2006, p. $2: 8$ ). This declaration underlines the importance for simplified donor policies and procedures as well as the need to eliminate the duplication of efforts of donor activities to make them more cost-effective. Furthermore, donors commit to "Provide timely, transparent and comprehensive information on aid flows so as to enable partner authorities to present comprehensive budget reports to their legislatures and citizens." (OECD, 2006, p. 2:15) in order to enhance the mutual accountability and transparency. On humanitarian aid side, in 201618 donor countries and 16 aid organizations, also demonstrated recognition of the need to improve the processes around aid delivery and signed the "Grand Bargain" which outlines 52 commitments across 10 work streams. One of them is dedicated to a "Greater transparency" with aid organizations and donors committing to ensuring "traceability of donors' funding throughout the transaction chain as far as the final responders and, where feasible, affected people" (Grand Bargain, 2016). The Inter-Agency Standing Committee's (IASC) endorsement of five Commitments to Accountability to Affected Populations (CAAP) in 2011 is yet another example of efforts to improve the transparency and accountability in the development aid sector. These commitments have a stronger focus on beneficiaries: "Provide accessible and timely information to affected populations on organizational procedures, structures and processes that affect them to ensure that they can make informed decisions and choices" (IASC, 2013).

The western public and the media also demands businesses, governments and non-profit organizations to be more transparent and accountable (OECD, 2005). According to Global Tolerance research, almost three quarters of people across the UK wanted to see more transparency and $81 \%$ more accountability from governments, businesses and non-profits (Global Tolerance, 2015). Requests for more accountability also correlate with the growing scale of non-profit organizations and their financial flows (Melendéz, 2001).

Currently there are various mechanisms which are trying to ensure both transparency and accountability to different stakeholders. Such mechanisms include regulations and policies; volunteering disclosure using frameworks, standards 
and certification processes; and an evaluation performed by independent watchdogs. The first one is mostly used just to comply with existing laws, the second level is voluntary disclosure tailored to important constituencies such as funders and beneficiaries, and the last one is conducted by third parties who are looking at available reports and other information and then consolidate this data to provide an overview of the efficiency and effectiveness of aid organizations. The IATI framework, for example, which "brings together governments, multilateral institutions, private sector and civil society organizations and others to increase the transparency and openness of resources flowing into developing countries" ${ }^{1}$ is widely used by donor governments and big multilateral institutions for voluntary public disclosure. According to their 2016 report, over 500 organizations now use it and the whole initiative is supported and governed by multiple stakeholders, including United Nations (IATI, 2016). In most cases the usage of IATI is on a volunteer basis, however some development agencies like DFID (The UK government's Department for International Development) already require from all organizations receiving and spending their funds to use this framework. The "Grand Bargain" also considers IATI as currently the most advanced tool for sharing data on funding (Grand Bargain, 2016). All reports are recorded in an IATI Registry and then published on a d-portal-a country-based information platform that provides user-friendly information on resource flows. However, it does not offer any analysis or interpretation of data. Publish What You Fund, an independent not-for-profit organization tries to address this concern. They encourage visibility and quality of development aid data so that it could then be effectively used in making decisions. They do so by engaging in research and advocacy. In addition, they created the Aid Transparency Index which is "the only independent measure of aid transparency among the world's major development agencies" 2 . It analyzes information provided to IATI, reports submitted by organizations on their websites and independent surveys against a certain number of criteria and then provides an annual overview and ranking of how these big donors performed. Such consolidated information allows interested parties to see and compare information on development aid financing and the accountability regimes of different donors.

Many other tools focusing on specific stakeholders exist, however they do not necessary "talk" to each other. Lack of clarity about how different accountability processes could complement each other has been identified as one of the challenges in implementing the Grand Bargain (Metcalfe-Hough et al., 2018, p. 2). In addition to that, the complexity of different reporting mechanisms and auditing processes makes them costly (Melendéz, 2001). Tracking funds, collecting information, learning about changing legal requirements and new tools and filling reports are complex processes which require time, trained staff and money. These processes become even more complex

${ }^{1}$ IATI (2018). About IATI. Available online at: https://www.aidtransparency.net/ about (accessed September 18, 2019).

${ }^{2}$ The Aid Transparency Index (2018). Publish What You Fund. Available online at: http://www.publishwhatyoufund.org/the-index/ (accessed April 1, 2018). when there are many different actors involved in the financial flows. Thus, it is argued that the greater transparency comes at a cost to beneficiaries, since resources which could be used at the frontline have to be directed to the back-office (Melendéz, 2001; Breen, 2013). It is worth remembering that greater transparency allows for aid-receiving governments to make more informed decisions (Publish What You Fund, 2010), and for the local population to hold their governments accountable (McGee, 2013). However, most of the times, the target populations have very little input in the accountability system and in turn, the reporting systems are not attuned to their needs.

The disclosure of any information has limitations and it should be carefully assessed "where and how it works" to ensure its effectiveness (Cucciniello et al., 2017, p. 43). Several studies have demonstrated that in some cases less but more focused information is likely to deliver the same or better results compared to more comprehensive disclosure (Hood, 2007; Etzioni, 2010; Breen, 2013; Bauhr and Grimes, 2014). Producing too much data could also be used as a strategic tactic to hide important facts in the noise (Hood, 2007; Grimmelikhuijsen, 2011). Even if not done deliberately, a lot of valuable information tends to be buried under the flow of data in complex reports and the average citizen is not equipped to understand such complexity (Melendéz, 2001; Etzioni, 2010). By releasing big amount of data, organizations demonstrate, however, their compliance with laws and try to create an image that they have nothing to hide. This situation puts the relevant stakeholders into an uncomfortable position-they see the data is available, however without the ability to fully comprehend and decipher it, they cannot determine if a project is meeting their expectations. Hence, this results either in public confusion about the data (Etzioni, 2010) or a false trust and the illusion of knowing that comes from the idea/mantra that "more transparency is better." Hence, some scholars argue that only a two-way communication with interpretation and quality control mechanisms in place can produce effective transparency (Hood, 2007) and others emphasize the importance of finding the right balance that does not become an operational distraction while creating a meaningful public accountability regime (Melendéz, 2001; Breen, 2013).

\section{BLOCKCHAIN TECHNOLOGY'S ROLE}

Blockchain Technology (BT), a family of technologies and solutions based on a distributed ledger technology, is being proposed as having the potential to transform the development aid sector by enhancing transparency, providing cost savings and creating new ways for monitoring and tracking impact (Davies, 2015; Galen et al., 2017; Hernandez, 2017; Pisa and Juden, 2017; Zwitter and Boisse-Despiaux, 2018).

Literature around development sector emphasizes that BT could open possibilities to facilitate sharing data between different humanitarian agencies in an easier and less costly way, while at the same time protecting sensitive beneficiary information (Galen et al., 2017; GSMA, 2017). It is argued that BT could help reduce bureaucracy and facilitate coordination of 
actions amongst donors which all have their own agendas and in return this would permit to identify funding gaps in development aid sector (Galen et al., 2017; Pisa and Juden, 2017).

However, implementations of BT based applications in development sector would inevitably face some challenges. Researchers argue that tackling political issues and power relations might take more time than implementing the technology itself (Galen et al., 2017; Hernandez, 2017; Zambrano, 2017). This is especially true if donation receiving organizations and governments are making no efforts to be more transparent and when there is no collaboration and open dialogue on their part.

In addition, digital illiteracy among beneficiaries as potential providers, evaluators and users of information has been identified as an important stumbling block which must be considered when implementing BT projects to avoid opportunistic behavior by powerful actors (Galen et al., 2017; Pisa and Juden, 2017; Coppi and Fast, 2019). This is especially prevalent in developing countries and among the most deprived populations that the development organizations attempt to reach. In addition, some academics have raised concerns regarding ethical issues related to testing new BTs on vulnerable groups and dangers of leaking their private data to the wrong hands (Cook, 2018; Juskalian, 2018; Zwitter and Boisse-Despiaux, 2018). There are concerns regarding security of private data of beneficiaries in digital registries, such as digital IDs. Initiatives which are collecting vast amounts of personal data of refugees to provide them with digital IDs have been frequently questioned. Also, Blockchain Technology is like any database, only a tool, which means that reliability of records would highly depend on how they were created in the first place (Pisa and Juden, 2017).

Pisa and Juden (2017) have identified that in the quest to make aid disbursement more transparent, there are two main models of BT adaptations: the first one is sharing data about project funding and its metrics; and the second one is conducting aid payments directly over blockchain. However, like other scholars (Galen et al., 2017), they highlight that the biggest challenge for BT initiatives for the development aid sector lies within their lack of scalability. Development organizations, non-profits and governments tend to have a slow and riskaverse bureaucratic nature which might hinder the adaptation of innovative and disruptive technologies. Other scholars (Zwitter and Boisse-Despiaux, 2018; Coppi and Fast, 2019) highlight the lack of prerequisites, such as infrastructure and regulations, in developing countries as another obstacle to the scalability of this technology.

More recent research (Zwitter and Boisse-Despiaux, 2018; Coppi and Fast, 2019) suggests that lack of common legislative framework is partly hampering the BT's adoption for aid development and in successfully addressing the related concerns about privacy and scalability. They emphasize the need for monitoring and evaluation guidance to improve knowledge sharing around BT and argue for the creation of a repository of ongoing initiatives to help stakeholders make more informed decisions and to facilitate BT development. Coppi and Fast (2019) also cite the lack of knowledge about this technology in the aid development sector as one of the obstacles for its adoption.
The Diffusion of Innovation (DOI) theory, which was proposed by Rogers (1962), seeks to explain the adoption process of innovative ideas, products or services in a social system over time. It is a well-established framework which has been widely used in various academic fields (Wani and Ali, 2015).

According to this framework (Kaminski, 2011; Wani and Ali, 2015), diffusion is the process by which an innovation is communicated over time among the participants of a social system which fall in one of the five adopter categories: innovators, early adopters, early majority, late majority and laggards. Their profiles differ one from each depending on their risk appetites, willingness and means to experiment with new technologies and based on the point of time they are ready to adopt an innovation. However, regardless of the nature of people and organizations, the characteristics of an innovation itself contributes to the rate of adoption in the society. DOI theory identifies five of them: relative advantage, compatibility, complexity, triability, and observability. The relative advantage reflects to what degree the innovation is perceived to be more advantageous than the one in practice in different terms, such as economic profitability, time saving or social prestige. Compatibility is related to an innovation's consistency with perceived needs, socio-cultural values and beliefs. Complexity covers the level of difficulty to understand or use an innovation. Triability is the degree to which the potential users could test and try a new innovation before actually adopting it. Finally, observability refers to the visibility of the results of an innovation and communication about them to the prospective users.

In our analysis we draw upon these five characteristics of innovation identified by the DOI to summarize and analyze our findings.

\section{METHODOLOGY}

Our study was organized around the question of what type of barriers and enablers currently exist for the Blockchain Technology to become adopted by the development aid sector to improve financial aid flows based on the donors' views.

To answer this question, we looked at discourses from different sources and combined them with our own perspectives constructed from analyses of wide-ranging empirical material.

Our primary source was the analysis of how the five biggest donor governments: US, UK, Japan, Germany, and France (OECD DAC, 2019) and their agencies articulate their approach to Blockchain Technology. With the help of data of the Publish What You Fund website, we identified the main development aid agencies (Table 1) within each of the five governments and proceeded looking for any papers and articles related to blockchain on their webpages by using their websites' integrated search tool and keywords "blockchain" and "distributed ledger." Following this research, we identified 7 reports and, in the case of Germany, 1 paper and 1 article. We also included reports which were issued by other government agencies about Blockchain, when we believed that they could influence the discourses within the respective development aid agencies. For example, we included in our analysis The American Council for Technology 
and Industry Advisory Council (ACT-IAC) report, developed by Blockchain Working Group, representing more than a dozen federal agencies in the US, formed at the request of the General Services Administration (GSA). All our information sources are listed in Table 2.

In addition, we included the following multilateral organizations in our analysis: EU, World Bank Group, UNDP, UNICEF, and UN OCHA (Table 3). The reason for choosing those was that they are responsible for a significant portion of development aid according to Publish What You Fund ${ }^{3}$. Finally, we have chosen OECD since it can shape policies of 36 member countries of which the majority dedicate some funds to development aid. In addition, they have been an influential platform for discussions around aid transparency.

This paper also benefited from one of the author's Master thesis (Rugeviciute, 2018) for which she conducted interviews with different actors involved in the development aid sector (Table 4) and analyzed two start-ups focused on technological solutions for aid transparency.

All interviews were semi-structured and lasted between 30 and $60 \mathrm{~min}$ (all conducted by Rugeviciute). Interviews were semi-structured. Recognizing that all the actors had different experiences with blockchain and the development aid sector, and also the changing conceptual focus on the research project, the structure of the interviews changed depending on who was interviewed and over time. All the transcriptions and notes were communicated back to the interviews. This provided an opportunity for the interviewees to clarify some of their statements if they felt it was needed.

For all our qualitative material, we used a coding method in which we marked reoccurring ideas relevant to our research question based on the below set of questions:

1) Does it mention Blockchain Technology's or Distributed Ledger Technology's potential usage in the development aid flows?

2) What is the proposed definition of Blockchain Technology?

3) What Blockchain Technology's aspects identified to be useful for development aid? Why? Any proofs/examples?

4) What Blockchain Technology's technical aspects identified as stumbling blocks for its usage (general, not necessarily connected with the aid development sector)? Why? Any proofs/examples?

5) What risks and barriers (other than technical) associated with Blockchain Technology for the aid development mentioned?

6) What keys for success for the adoption/implementation of Blockchain Technology identified? Are they relevant only for the development aid sector? Why are they important?

7) Which types of blockchains analyzed (if any)?

8) What is a framework proposed for use of Blockchain Technology (if any)?

9) Which Blockchain characteristics are seen to be most relevant for the development aid sector? Why?

\footnotetext{
${ }_{3}^{3}$ Multiple Agencies (2018). Publish What You Fund. Available online at: https:// www.publishwhatyoufund.org/the-index/2018/multiple/ (accessed April 5, 2019).
}

We proceeded with comparing these ideas and eventually merging them into broader and more conceptual themes. We grouped our findings into three main categories: discursive, technological and institutional barriers and enablers.

We also analyzed two start-ups: Alice and Disberse based on different sources, such as their white papers, websites and interviews with their representatives. These start-ups were chosen due to their focus on enabling more transparency in the development aid sector using Blockchain Technology, their involvement with different donors. Both have been successful with their first proof of concepts and are working toward scaling their technological solutions. The insights from these two case studies helped us understand better the donors' attitude and roles in blockchain based projects.

Our empirical investigation, however, has limitations. We have selected only the biggest donor governments and multilateral institutions based on their activities in development financing/aid. Due to the time constraints we had only few interviews with representatives from large development aid agencies and those interviewees were not necessarily directly involved with the experiments of Blockchain Technology within those organizations. In addition, in our research we covered only the material found in the reports produced or commissioned by government donors and multilateral organizations and we have not covered the on-going initiatives on the ground. Finally, we narrowed down our focus to the development aid flows, however, the adoption of BT also affects other development aid domains.

\section{RESULTS}

Our research explored the barriers and enablers for the adoption of Blockchain Technology in the development aid sector based on the donors' point of view. We divided our findings into discursive framings, technological and institutional categories. Discursive framing category covers the stated beliefs of different key actors in the space of development aid about Blockchain's benefits and its main obstacles. Technological category covers the attributes of Blockchain which are either desired in the development aid sector or seem to pose a barrier. Finally, the institutional barriers and enablers consider the coordination bodies/processes, standards, norms and regulations for Blockchain Technology in development aid.

\section{Discursive Barriers and Enablers}

Based on our interviews and analysis of documents from donors, here we discuss the discursive dynamics around Blockchain's definition and qualities which could benefit the development aid sector and those that could hamper it.

\section{No Common Definition}

Blockchain Technology does not have a single definition universally used between experts. This also applies to analyzed reports (Figure 2). Definitions vary from defining Blockchain as a mechanism (Nomura Research Institute, 2016) to being a type of data structure (Natarajan et al., 2017). The majority of papers separate "Blockchain" from "Distributed Ledger Technology." However, this is not the case in reports produced by the France 
TABLE 1 | Main development agencies.

\begin{tabular}{|c|c|c|}
\hline Country & Development agencies & Their websites \\
\hline \multirow[t]{2}{*}{ US } & MCC & https://www.mcc.gov/ \\
\hline & USAID & https://www.usaid.gov/ \\
\hline \multirow[t]{2}{*}{ UK } & DFID & https://www.gov.uk/government/organisations/department-for-international-development \\
\hline & FCO & https://www.gov.uk/government/organisations/foreign-commonwealth-office \\
\hline Germany & KFW & https://www.kfw.de/KfW-Group/ \\
\hline \multirow[t]{2}{*}{ France } & AFD & https://www.afd.fr/fr \\
\hline & MEAE & https://www.diplomatie.gouv.fr/en \\
\hline
\end{tabular}

TABLE 2 | Blockchain related papers by 5 biggest donor governments.

\begin{tabular}{ll}
\hline Country & Blockchain related reports/studies \\
\hline US & Report: "Primer on Blockchain" by Paul Nelson commissioned by \\
& USAID (Nelson, 2018) \\
& Report "Enabling Blockchain Innovation in the U.S. Federal \\
& government" by ACT-IAC (Abdolrahimi et al., 2017) \\
& Report "Distributed Ledger Technology: beyond block chain" by UK \\
GK & Rovernment Chief Scientific Adviser (Walport, 2016) \\
& Moport "Blockchain for Development: Emerging Opportunities for \\
& funded by DFID (GSMA, 2017) \\
& Report "Survey on Blockchain Technology and Related Services" by \\
Nomura Research Institute contracted by METI (Nomura Research \\
Institute, 2016)
\end{tabular}

Stratégie (the Think Tank of the office of the French prime minister) and by the EU Blockchain Observatory \& Forum. The most common recurring descriptions in Blockchain's definitions were: Distributed, No central authority, Blocks, Cryptographic. Papers which gave definitions for Distributed Ledger Technology added keywords such as Database and Shared.

Overall, our study shows that, ideas around Blockchain, its attributes and its role are quite fragmented and diverse, and there is not much possibilities and platforms for exchange and engagement among these different articulations.

In the following sections, even if we acknowledge that there is a difference between Distributed Ledger Technology (DLT) and Blockchain Technology, for simplification reasons we are using only a term Blockchain Technology (BT) which encompasses a specific enactment of DLT.

\section{Discourses Around BT Qualities}

Blockchain's benefits were frequently articulated in terms of cost reduction through removing intermediaries and decreasing
TABLE 3 | Blockchain related papers by multilateral institutions.

\begin{tabular}{ll}
\hline $\begin{array}{l}\text { Multilateral } \\
\text { Institutions }\end{array}$ & Blockchain related reports/studies \\
\hline World Bank & \\
Group (WBG) & Report "Distributed Ledger Technology (DLT) and \\
EU & Blockchain" (Natarajan et al., 2017) \\
& Reports "Blockchain for Government and public \\
& services" and "Blockchain and the GDPR" prepared \\
& by the European Union Blockchain Observatory \& \\
& Forum (Lyons et al., 2018a,b) \\
& Report "The Future is Decentralized" (Blockchain \\
UNDP & Team, 2018) \\
& Paper "Un-chained: experiments and learnings in \\
UNICEF & crypto at UNICEF" (Fabian, 2018) \\
& Report "Blockchain for the Humanitarian \\
UN-OCHA & Sector-Future Opportunities" by DH Network (Ko \\
& and Verity, 2016) \\
Working Papers on Public Governance "Blockchains \\
Unchained: Blockchain Technology and its Use in \\
the Public Sector" (Berryhill et al., 2018) \\
OECD
\end{tabular}

investments for information conservation and retrieval. This was in contrast to the public discussions about the role of Blockchain in improving public accountability in development. Additionally, increased auditability was highly cited by both government donors and multilateral institutions as a potential benefit of adopting Blockchain Technology.

The interviewees involved with development of BT for development frequently indicated that the public availability of records, their immutability and cost savings were the primary motives why this technology was a great tool to increase transparency and accountability between projects and Western donors. The most important aspect for the majority of interviewees, representing start-ups and those involved with development institutions, was the fact that BT could enable greater control to track transactions, especially where there were many actors involved. One of the interviewees, involved with a start-up Curado which decided against implementation of BT, emphasized that: "traceability of money becomes way more relevant with the likelihood that someone's trying to put it in their own pocket." Since they were dealing with local charities which do 
TABLE 4 | List of interviews.

\begin{tabular}{|c|c|c|}
\hline $\begin{array}{l}\text { Date of the } \\
\text { interview }\end{array}$ & Interviewee & Length of interview \\
\hline 23 January 2018 & A representative of Alice.si & $57.19 \mathrm{~min}$ \\
\hline 02 February 2018 & A representative of Disberse & $50 \min$ \\
\hline 19 February 2018 & $\begin{array}{l}\text { A representative of Publish What } \\
\text { You Fund }\end{array}$ & $28.42 \min$ \\
\hline 19 March 2018 & A former employee at DFID & $35.26 \mathrm{~min}$ \\
\hline \multirow[t]{2}{*}{ O3 March 2018} & A representative of Curado & $34.26 \mathrm{~min}$ \\
\hline & $\begin{array}{l}\text { A person involved with an } \\
\text { international development } \\
\text { organization }\end{array}$ & Email exchange \\
\hline
\end{tabular}

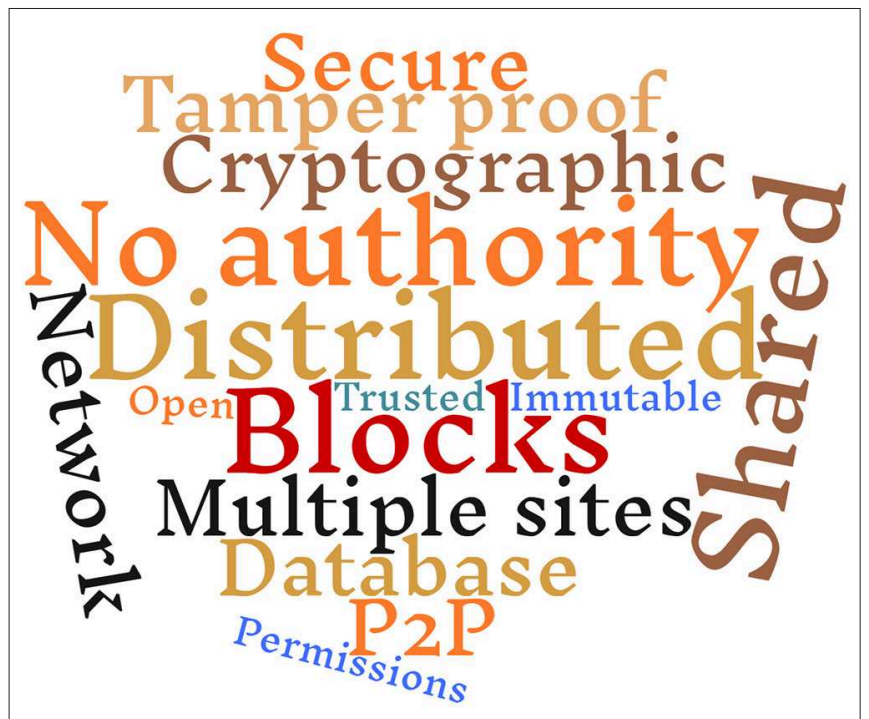

FIGURE 2 | Words used in Blockchain's definitions.

not have a complex money flow chain, the likelihood of deliberate misuse of funds was smaller, hence according to him, BT would not add much value. This argument was also evoked in the EU report: "Blockchain Technology is very good at creating trust in information and processes in situations where there are large, heterogeneous sets of stakeholders or users" (Lyons et al., 2018a, p. 10). The potential for Blockchain to increase transparency and allow to track transactions was equally highly cited by both government donors and multilateral institutions.

However, the rest of the identified Blockchain's qualities varied a lot between the government donors and multilateral institutions. None of the analyzed donor government sources mentioned the advantage of BT to assure that benefits would reach the intended beneficiaries. This potential, however, was cited by the majority of multilateral institutions and confirmed by the start-up representatives who were working with aid organizations. The likelihood of removing frictions and barriers between different actors was also identified more by the multilateral institutions than the government donors.
BT being an innovative way which could interest different type of investors was mentioned by a variety of actors as one of the reasons why this technology is attractive. UNICEF emphasized the ability to attract new donations in crypto-money as it happened with Pineapple Fund donating \$5 million Bitcoin to charities in 2018 (Terzo, 2018). Whereas, Start-ups Alice and Disberse mentioned that their usage of Blockchain Technology helped to attract the attention of crypto-investors.

The other qualities, such as "Understanding patterns and trends of transactions," "Reducing system-wide complexity," or "Lessen the chance of inconsistencies across different actors" were mentioned only by few sources.

Table 5 summarizes the main discursive trends around BT qualities identified from the cases of start-ups and from the reports of donor organizations.

\section{Discourses Around Obstacles to BT Adoption}

Based on our research, we identified three main discourses around the current obstacles in the BT's development sphere (Table 6) which are perceived to hinder the adoption of this technology.

To begin with, lack of understanding of Blockchain Technology has been heavily cited as a barrier for its adoption. Almost all the reports mention that majority of the people working in government agencies do not fully grasp it and that there is a need for a better education and training around it. In addition, converting Blockchain Technology into usable services requires higher trust in technology from people than they are used to have. Even if there is quite a lot of media coverage around Blockchain, the concepts surrounding it are complex and difficult to comprehend for non-technical people. The quantity of different ideas and potential use cases floating in the literature demonstrate the struggle to easily conceptualize the idea behind this technology. This was confirmed in our interviews, where almost everyone mentioned the complexity of BT. Furthermore, Blockchain Technology is almost always linked to the turmoil of the Bitcoin platform. Bitcoin was also the most frequently mentioned type of Blockchain in the reports we analyzed.

The second identified barrier was the obscurity around the potential cost-benefit of BT's adoption. However, this was mostly mentioned only by the donor governments and confirmed by the interviewees who were in dialog with them. It is still unclear what financial investments are required to test and implement Blockchain Technology and if they would pay off in the longterm. Furthermore, currently there is a huge number of ongoing projects in this sphere, with many variations of this technology-different consensus mechanisms, different access rules and data storage. The whole activity is quite fragmented with not many actors clearly sharing their learnt lessons (Haan, 2018). This led to most of the reports to emphasize the need for an effective communication between different parties to successfully advance in BT developments. Three practitioners in international development researched 43 blockchain use-cases and could not identify any evidence of the results blockchain was claimed to have achieved (Burg et al., 2018). This further demonstrated the need for more effective sharing of lessons learnt from these projects. 
TABLE 5 | Benefits of Blockchain Technology based on donors' discourses.

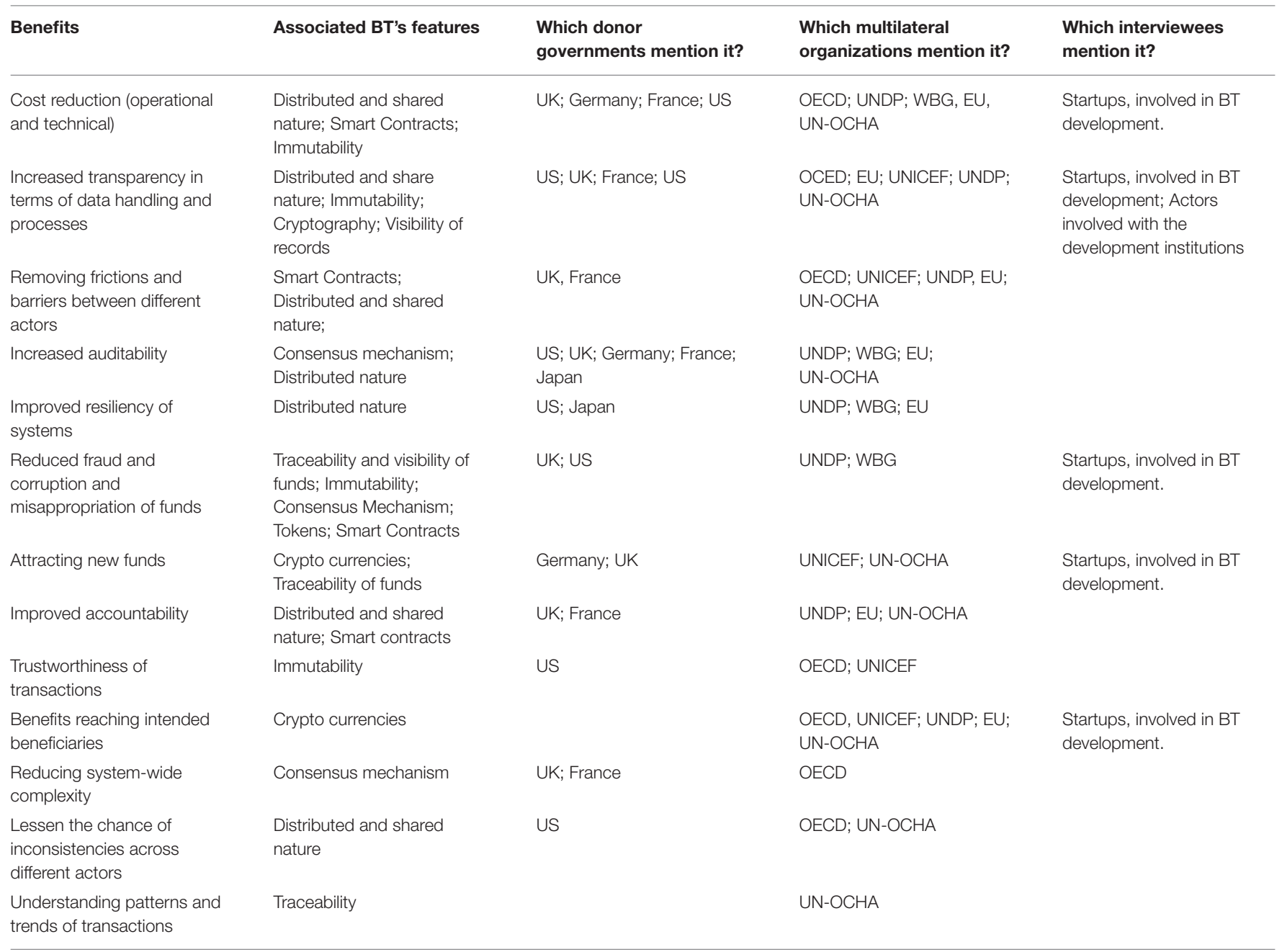

Resource intensiveness of implementation was another barrier mentioned by some actors. According to Microsoft (Bajpai, 2018), developing a proof of concept using Blockchain Technology is time consuming and costly-it takes around 3 months and can cost as much as $\$ 300 \mathrm{~K}$. Furthermore, some reports and interviewees questioned the need to replace the legacy systems which are currently in place run by donor agencies, considering the related cost and administrative burden. Finally, German KfW (German state-owned development bank) also points out the lack of financial incentives for the private sector to develop appropriate applications for the development sector, as a barrier (Kemper and Sattelberger, 2017).

Overall Blockchain is seen as an effective technology for process control in complex/multi-actor settings which can allow to increase the accountability of its functions. However, we observed a fragmentation of discourses around the definition of BT and its potentials. Out of thirteen identified BT qualities, only three of them were mentioned by the majority of both government donors and multilateral organizations. We believe this reflects the complexity of the technology with each of the actors perceiving the BT slightly differently, and also lack of sufficient engagement/exchange among these actors. Such discursive silos could be a challenge for its adoption which is also reflected by the government donors articulating "lack of communication" as one of the obstacles to BT's adoption.

\section{Technological Barriers and Enablers Technological Enablers of Adoption}

Blockchain Technology has many different technical characteristics and different reports from donor organizations went to different lengths trying to explain them. The majority of them touched the concepts of: public vs. private vs. consortium blockchains, different consensus mechanisms and smart contracts. Bitcoin blockchain was quoted almost in every paper, with Ethereum blockchain being the second most quoted example. Other examples of blockchains, such as Hyperledger Fabric, Corda, Ripple and Dash were mentioned only by a couple of papers. The same was evident from the interviews: Bitcoin and Ethereum blockchains were known by a majority but other types of blockchains were not even mentioned. This reflects one of the subproblems associated with "The lack of understanding of BT" identified in the previous category: "Blockchain Technology 
TABLE 6 | Perceived barriers concerning the BT's development.

\begin{tabular}{|c|c|c|c|c|}
\hline Obstacle & Associated problems and risks & $\begin{array}{l}\text { Which donor } \\
\text { governments mention it? }\end{array}$ & $\begin{array}{l}\text { Which multilateral } \\
\text { organizations mention it? }\end{array}$ & $\begin{array}{l}\text { Which interviewees } \\
\text { mention it? }\end{array}$ \\
\hline \multirow[t]{5}{*}{$\begin{array}{l}\text { Lack of } \\
\text { understanding of } \\
\text { BT }\end{array}$} & $\begin{array}{l}\text { Difficult public debate between } \\
\text { different stakeholders and with } \\
\text { citizens. }\end{array}$ & UK & OECD; UNDP UN-OCHA & $\begin{array}{l}\text { Startups, involved in BT } \\
\text { development; Actors } \\
\text { involved with the } \\
\text { development institutions }\end{array}$ \\
\hline & $\begin{array}{l}\text { Blockchain Technology is too often } \\
\text { linked to the turbulence of the Bitcoin } \\
\text { platform }\end{array}$ & & OECD; WBG; UN-OCHA & $\begin{array}{l}\text { Startups, involved in BT } \\
\text { development; Actors } \\
\text { involved with the } \\
\text { development institutions }\end{array}$ \\
\hline & Shortage of technical expertise & UK; US & OECD; UNICEF; WBG & $\begin{array}{l}\text { Actors involved with the } \\
\text { development institutions }\end{array}$ \\
\hline & $\begin{array}{l}\text { Many people might not be ready to } \\
\text { have such high trust in technology }\end{array}$ & US & & \\
\hline & $\begin{array}{l}\text { Current lack of knowledge around } \\
\text { crypto money and other digital assets } \\
\text { drive banks (especially in France) to } \\
\text { automatically refuse the account } \\
\text { management of enterprises which } \\
\text { hold these digital assets. }\end{array}$ & France & & \\
\hline \multirow{2}{*}{$\begin{array}{l}\text { Perceived cost of } \\
\text { BT's } \\
\text { implementation }\end{array}$} & Return on investment is unclear & US; UK; Germany; Japan & OECD & $\begin{array}{l}\text { Actors involved with the } \\
\text { development institutions }\end{array}$ \\
\hline & $\begin{array}{l}\text { Legacy IT systems are serving critical } \\
\text { roles }\end{array}$ & US & & \\
\hline $\begin{array}{l}\text { Lack of } \\
\text { communication }\end{array}$ & $\begin{array}{l}\text { Fragmented activity in BT sphere: } \\
\text { many POCs and many blockchains }\end{array}$ & UK, US, Japan & & \\
\hline
\end{tabular}

is too often linked to the turbulence of the Bitcoin platform" (see Table 6).

A working paper by OECD, a report by WBG and reports by US ACT-IAC and USAID propose frameworks/questionnaires to use when deciding if Blockchain Technology should be considered in a project. However, overall, most of the papers avoid giving recommendations about what type of Blockchain technology should be used by the development aid sector. A few of them identified and reasoned which Blockchain Technology's technical characteristics would be more useful for dealing with financial flows in the public and/or the development aid sector.

Permissioned ledgers were perceived to be more suitable for the public sector (cited in: a paper by OECD, in UK reports by DFID and UK Government Chief Scientific Adviser, a report for Japan METI and UN-OCHA) to ensure the correct rules for who and how is allowed to use the system. It was also evoked that having a permissioned ledger might help to establish procedures for correcting erroneous transaction which due to the immutable nature of a blockchain is not easy to do.

The OECD also suggested to choose a consensus method which could "take into account government rules and laws" (Berryhill et al., 2018, p. 19), such as Proof of Authority or Round Robin.

Smart contract features were also perceived as especially desirable for the development aid sector with its ability to automate the process (mentioned in papers by OECD and UNICEF) for the disbursement of funds and for eligibility verification for the beneficiaries. It was also perceived that having an open source code and thus making the logic behind a smart contract open for everyone would increase transparency. Multisignature wallet (cited by UNICEF) as well as the integrity of transactions (a report by UK Government Chief Scientific Adviser) were also named as features which could reduce fraud and misappropriation of funds.

Finally, the use-cases of Alice and Disberse reaffirm the need to have an easy to understand interface for the users of Blockchain based systems in order to reduce the gap between the development and technological worlds.

\section{Technological Barriers to Adoption}

More technically savvy interviewees were in unison with the majority of papers that Blockchain Technology is still an immature tool with many technological limitations (Table 7). A report by UK Government Chief Scientific Adviser, for example, emphasizes the importance of developing systems that could be upgraded with the new hardware or with more secure algorithms over the time to avoid obsolescence linked to the immaturity of BT. In addition, this technology is not designed for large amounts of general data storage, such as documents, videos, images, which, according to the OCED working paper, means there should be a careful design prior its implementation.

For the Blockchain Technology to achieve its purpose and improve financial aid flows there is a need to ensure that the prerequisites exist in the receiving countries. Ensuring the basic technical infrastructure is the first step. According to reports produced by UK Government Chief Scientific Adviser and US 
TABLE 7 | Technological barriers.

\begin{tabular}{|c|c|c|c|}
\hline Obstacle & Associated problems and risks & $\begin{array}{l}\text { Which donor } \\
\text { governments } \\
\text { mention it? }\end{array}$ & $\begin{array}{l}\text { Which multilateral } \\
\text { organizations } \\
\text { mention it? }\end{array}$ \\
\hline & Lack of telecom infrastructure & & \\
\hline $\begin{array}{l}\text { Limited impact } \\
\text { monitoring data } \\
\text { sources }\end{array}$ & $\begin{array}{l}\text { Limited scope of atomization due to limits of } \\
\text { reliable impact monitoring data sources } \\
\text { Data quality depends on the inputs }\end{array}$ & UK & \\
\hline Security concerns & $\begin{array}{l}\text { Loss of private keys } \\
\text { Many international actors with different } \\
\text { authentication systems in place Cyber-attacks }\end{array}$ & UK; France; US & WBG \\
\hline $\begin{array}{l}\text { Environmental } \\
\text { challenges }\end{array}$ & $\begin{array}{l}\text { High consumption of energy for a Proof of } \\
\text { Work protocol }\end{array}$ & France & WBG \\
\hline $\begin{array}{l}\text { Isolated } \\
\text { Blockchain } \\
\text { systems }\end{array}$ & $\begin{array}{l}\text { Difficult to move from legacy systems } \\
\text { Question of compatibility with other systems }\end{array}$ & UK; France; US & WBG \\
\hline
\end{tabular}

ACT-IAC, a careful planning must be also undertaken to ensure the availability of the system when hit by natural or human-made disasters in the receiving countries.

There are also questions related to the immutability of BT. Even though it promises to reduce fraud and to increase transparency, due to its complexity it can increase the chances for genuine errors. In addition, it raises issues related to "the right to be forgotten" and the new GDPR law passed by EU. EU Blockchain Observatory and Forum has recently published a paper (Lyons et al., 2018a) on the latter question trying to address these issues where one of their main recommendations is simply to avoid storing personal data on a blockchain. Data quality has been also mentioned by few interviewees and reports. For example an OECD paper mentions (Berryhill et al., 2018, p. 30): "the quality of the data that is input at the origin will directly affect quality of the data on a Blockchain and the quality of the results derived from that data." In the example of the Disberse start-up, they promise visibility on tracking funds however they stress that this is not a solution to corruption. After all, once the money is cashed out, the visibility of where it goes and what is being done with it is lost.

Questions about security and privacy have also been evoked by different government donor reports. They inquire how to safely determine the identities of users and ensure the correct trade-off between transparency and confidentiality and to protect sensitive data related to vulnerable communities. A report by UK Government Chief Scientific Adviser suggests that there is a need for Federated Identity Management which would meet international standards to ensure authentication across multiple authorities. A carefully designed authentication system is also needed to address cybersecurity questions to handle the loss or a potential theft of private keys which ensure secure access to a blockchain but cannot be changed as normal passwords.

In addition, since many of the development aid flows involve very large sums there is a need to develop systems which would be resilient against serious cyber-attacks. Even if BT is perceived to provide more resiliency due to its distributed nature, and if one of the nodes go down, others are still up and running, the report by UK Government Chief Scientific Adviser proposes that systems should be developed that they could be taken offline, have back-ups and different actors would carry out regular security infiltration tests.

Likewise, there is a need to carefully consider the trade-offs when choosing a Blockchain Technology: more transparency on a blockchain means less confidentiality, whereas more traceability of transactions leads to reduced anonymity. For example, currently many of the permissionless blockchains have a limited transaction speed. These problems could be better tackled by permissioned blockchains; however, in their report the World Bank Group argues, that this comes at the cost of transparency. Drawing from the case studies of Alice and Disberse, dependency on a public blockchain, such as the Ethereum platform might carry other risks. In the case of Alice, they have to be careful how they develop their own platform as they depend on Ethereum Gas, a measurement used to compute and pay for Ethereum's work, which is transacted in the Ethereum cryptomoney Ethos. The value of the latter can be at times very volatile. Disberse, on the other hand, already mentioned the considerations to move away from Ethereum and build their own permissioned blockchain. The volatility of cryptomoney was also a reason why both start-ups opted instead for the usage of escrow accounts, where the fiat money was held and their tokenized values 
TABLE 8 | Institutional barriers.

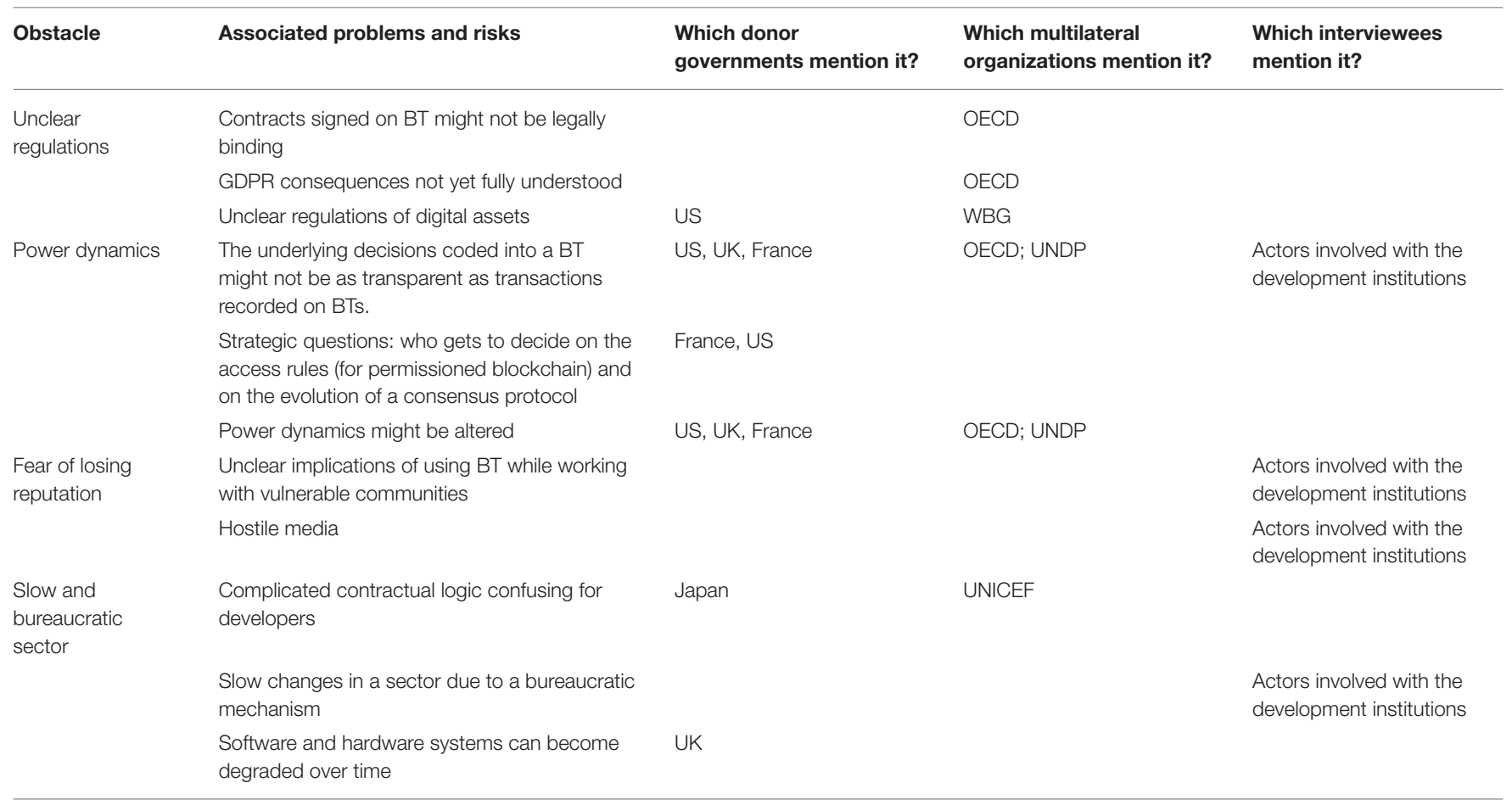

were circulating in the digital realm. The paper by UNICEF however argues that such practices limit the potential benefits of cryptocurrencies, such as speed and visibility of money once tokens are cashed out.

Finally, there are many types of Blockchains, and their development is still on-going. Different companies and institutions opt-in for different Blockchains. Therefore, the interoperability between blockchains has been named as one of the conditions for a success of this innovation (Botsman, 2017; Kohlhaas, 2017; Smith, 2017). Reports by UK Government Chief Scientific Adviser, France Stratégie, US ACT-IAC and WBG second this explaining that designing private, public and consortium blockchains in a way that they could "talk" to each other would help to move away from complex legacy processes. In addition, such reports emphasize the importance for the Blockchain systems to be developed so that they would be compatible with other legacy systems.

\section{Institutional Barriers and Enablers}

This last category groups the identified enablers and barriers for the BT's adoption which concern specifically the norms, rules and governance structures for BT in the development aid sector. Our definition of institutions which is consistent with contemporary thinking in neo-institutionalism (Scott, 2001) in other words includes both soft (norms and values) and hard (rules and standards) aspects of institutions.

\section{Institutional Enablers}

The need to be at the technological forefront and also to be perceived as accountable and transparent organizations are now well-established norms in the development sector, and they contribute to faster adoption of all accountability related technologies.

Interviewees involved in major international charities or donors like DFID emphasized that there is an appetite for innovation and a general desire to improve accountability processes in the development aid sector. The Disberse representative noted that overall this sector is very responsive to new ideas. This observation might have come out of their cooperation with the START network, which unites 42 international NGOs including Oxfam and Save the Children. The Alice representative said that big multilateral organizations which had finances to run an innovation department approached Alice because they provided solutions based on BT: "This is the perspective with which big companies are coming in "you tell me 'blockchain', okay talk to me." In addition, it was mentioned that these multilateral organizations approach them to learn about Blockchain Technologies and out of fear of being left behind. This was also reaffirmed by UNICEF's paper: "If this type of radical transparency and traceability becomes an assumption for international development money from both individual donors and governments, large organizations that depend on voluntary funding would do well to start understanding the intricacies of the new financial networks sooner rather than later" (Fabian, 2018, p. 35).

When it comes to donor governments, the OECD encourages them to build knowledge in this new technology and consider how it can affect their role. The World Bank Group also emphasizes that "waiting for 'perfect' DLT solutions is not necessarily an ideal approach for development organizations" (Natarajan et al., 2017) and the need for all actors to participate in fostering knowledge and experimenting with BT: "But 
understanding the true potential of DLT for development objectives requires not just research but also real-life applications and trials" (Natarajan et al., 2017, p. 12).

Similar drivers are observable in other industries. Major financial institutions, known to be slow to change due to their organizational complexity, are investing millions in learning how to best implement Blockchain Technology (Marr, 2018). Outlier Ventures, a UK-based venture firm, has created a corporate research tracker which describes BT activity for 293 companies (Corporate Tracker, 2018). These companies are from different industries: from aviation to telecom, from financial to retail and they all invest in some way in BT. This research tracker also demonstrates that already 16 companies, including IBM, Goldman Sachs and Mastercard have applied for patents related to BT. However, interestingly none of these companies have deployed their BT solutions into large scale production yet (Lannquist, 2018). This situation clearly demonstrates the mimetic pressures across different fields to be an active player in BT technological developments.

\section{Institutional Barriers}

Most of the donor governments together with the UNDP and WBG emphasized the importance of having effective governance structures and regulation in place to protect the broader interest of society and to smooth partnerships between and across governments and industry. The need to find the right balance between protecting the interests of different stakeholders who are using Blockchain Technology and avoiding encumbering the process of innovation was frequently mentioned. Many of the donors emphasize that governments should play a central role in overseeing and fostering the developments in Blockchain Technology.

The role of government might become especially important when considering the concerns related to the changes in power structures resulting from the implementation of BT. This question has been raised by many of the donors. It is not clear yet who would get to decide what should go into the code, especially in the case of smart contracts and consensus mechanisms, and who would be held responsible if something goes wrong. The development aid sector is especially vulnerable to misuse since they tend to serve the most fragile communities. The power dynamics might also be shifted with the arrival of new "crypto" intermediaries, such as Alice, AidCoin, or Helperbit. All of them aim to increase transparency for donors to track where their money goes. It remains to be seen what future role they will play vis-à-vis donors and beneficiaries. The potential for BT to alter the existing power structures, could be therefore seen as both an enabler and a threat to the development aid sector depending on the underlying motivations of actors.

Furthermore, a few actors mentioned the lack of a regulator's firm stand toward the BT's industry (Table 8). In the UK, the FCA is allowing start-ups like Alice to use a specially designed sandbox environment to test their solutions and provide proof of concepts. However, the future of regulation is not completely clear which also was perceived as another risk for development aid organizations to be involved in BT movement. Some reports have therefore proposed that governments should strive to integrate regulations in the $\mathrm{BT}$ codes since with the distributed nature of BT, regulators struggle to regulate such systems via traditional rule-based regulatory processes.

Interviewees who worked within development aid organizations also raised concerns about possible media backlash. One of them said "I think part of the challenge is no matter how good the donor agency was, unfortunately we are dealing with a fairly hostile media in relation to development assistance. $<. .>$ you therefore have a public, who are not currently inclined to believe into the value of aid, and are happy to go along with a media in disparaging it and undermining it." Reputation is important for both development agencies and charities to ensure they would be trusted by taxpayers, civil society, and beneficiaries. Having a hostile media which tends to prefer to report scandals instead of achievements puts development aid actors in a risk averse position. Articles, such as "Rohingya Crisis Highlights Blockchain Data Issues" (Cook, 2018) already emphasize associated dangers with UN WFP's tests of BT on fragile populations. Such cases show that minor implementation issues can attract a major negative media backlash. Hence, this creates a paradox: there is a desire to innovate however nobody wants to be the first mover as it means taking a bigger risk.

Finally, a few reports and all interviewees involved with international development institutions reaffirm the existing literature (Galen et al., 2017; Pisa and Juden, 2017) that development aid organizations, even if interested in innovations and taking the first steps to explore $\mathrm{BT}$, are very risk averse, bureaucratic and usually slow to change. The current development aid flows involve varied stakeholders: from donor and receiving governments to different civil society and inter-governmental organizations. Implementation of any changes around these processes inevitably requires fieldwide coordination and cooperation. In the light of this, some reports (OECD, UNICEF, UK DFID) emphasize the importance for governments and international organizations to partner with the private sector for the development of potential use cases and to help develop a cross-government knowledge base.

\section{DISCUSSION}

We divided our findings into three categories however it is clear that they do not represent isolated categories that could be addressed separately and that they are closely interlinked.

Our results reflect the intensification of debates around Blockchain Technology; characterized by a fragmentation in the discourses around definitions, and articulation of problems and solutions. The definitions of Blockchain Technology vary widely without a common agreement between donor governments and multilateral institutions. Almost all actors perceive Blockchain Technology as an enabler for a greater control to track transactions, increase auditability and minimize associated costs. Many of them cite the lack of understanding around it as the biggest threat for its implementation. However, the rest of benefits around the BT and existing obstacles are mentioned in a rather scattered manner. 
Lack of shared platforms for debate and knowledge sharing around Blockchain in the aid development sector seems to be an important factor driving this fragmentation. There are also some other factors enabling and sustaining this. Not all government reports have a strong focus on the development aid sector and for some governments, under analysis, reflections about BT are at a broader level and not within the development agency. They look at Blockchain's broader implementation within the government's various functions. This could explain why such Blockchain potentials as "benefits reaching intended beneficiaries" were mentioned only by multilateral institutions. Also, reports went to very different lengths in analyzing and discussing this technology. All of the actors shared their beliefs on BT's potentials in improving accountability on the financial flows. However, there was less discussion of its technical features as relevant to the development aid sector. This resonates with one of the identified barriers "lack of understanding of BT" and some of the sources mentioning the lack of technical knowledge around this technology in the governmental sector. These findings also support the views of previous research (Coppi and Fast, 2019) indicating that lack of understanding of BT poses challenges to its implementation within development organizations.

In the institutional category, we had more insight from the interviewees who were more open to discuss the regulatory environment and the normative factors in the development aid. They mentioned the slow-to-change and the conservative nature of this sector as a potential normative institutional barrier, but also a fear of being left behind in innovation which serves as a motivation to experiment in this field. This confirms the findings of the HPG Commissioned report research where "the desire to lead the way in testing new technology" (Coppi and Fast, 2019 , p. 1) has been identified as one of the motivations for adopting Blockchain Technology. Lack of sufficient national and transnational regulatory and standards' frameworks reinforces the inherent conservatism in this sector and hampers the "the desire to lead" translating to concrete and substantial projects.

Overall, most actors find Blockchain Technology to have a potential to respond to their values and needs. Such compatibility is one of the five attributes which according to the diffusion of innovation theory (DOI) highly influence the adaption of an innovation. As discussed in the beginning of this paper, there is a desire for an increased transparency and accountability in the sector. The perception that BT could increase auditability and make transactions more transparent and traceable respond to these needs. Furthermore, the majority of the multilateral organizations agree on BT's potential to remove frictions and barriers between different actors which could lead to the reduction of costs and complexity surrounding financial aid flows and ease the co-ordination challenges between different actors.

Nevertheless, without better established, shared and legitimate ideas of the costs and benefits of this technology, it is more difficult for a risk averse sector to move toward its adoption. Currently donor organizations have vast legacy systems in place and the benefits of their replacement with a new technology have to be very clear to outweigh the potential risks, conservatism and financial costs. Perceived relative advantage in terms of economic implications, and other rewards such as saving time and effort, to the existing or alternative systems is yet another attribute of DOI. The study findings show, however, that most of the donor governments question the positive return of an investment for this technology. The immaturity of this technology was also identified as a technological risk which encumbers the analysis of potential benefits of its usage.

A perception of innovation's complexity is a third concept in the DOI theory. Relying on our analysis, we argue that the diverse discourses around the potential benefits of BT and the lack of discussion around its technical aspects reflect that currently donors see this technology as being fairly complicated. This aspect has also been articulated in most of the interviews. Nevertheless, complexity does not always have to be a barrier in the innovation's adoption (Wani and Ali, 2015). Communication in this case plays an important role. It is imperative to find the best communication channels adapted to different audiences. This has also been advocated by a few multilateral organizations. Potential users need to be educated about what the technology does, its advantages and how to use it, whereas decision makers need to understand how this technology works in more technical detail, such as the differences between permissioned and permissionless blockchains, different consensus mechanisms and smart contracts.

In addition, communication is important in bringing visibility to the results of on-going testing and successful implementations of BT. Observability and triability are the last DOI attributes. The results show that a few donor governments are concerned with the risk of having very fragmented activity with many proofs of concepts which might overlap or create further ambiguity in the sector. These findings support the concerns expressed in previous research (Galen et al., 2017; Pisa and Juden, 2017; Zwitter and Boisse-Despiaux, 2018; Coppi and Fast, 2019) regarding the limited interoperability of systems and the lack of knowledge sharing between development aid actors. Silos of activities would only deepen the existing concerns, mentioned at the beginning of the paper, about a lack of clarity on how different processes could complement each other in the development aid sector. Furthermore, visibility on BT's developments is important for the beneficiaries. The results of our study add to the evidence (Zwitter and Boisse-Despiaux, 2018; Coppi and Fast, 2019) regarding the need to ensure that a suitable regulatory framework needs to be in place to effectively mitigate the risks associated with data protection/privacy.

Finally, potential power shifts resulting from BT implementation also plays an important role in its adoption. With BT's decentralized systems and the introduction of new players in aid flow governance, the politics of visibility and accountability will be heavily affected by BT use in the aid development sector leading to resistance from those in a losing position.

\section{CONCLUSIONS}

Blockchain Technology and its promises to cut down costs and increase transparency has drawn attention from all sectors, including development aid. In this empirical investigation 
we aimed to foreground the discursive, technological and institutional enablers and barriers for its adoption in the development aid sector.

Using the five qualities of an innovation which, according to the Diffusion of Innovation theory (Wani and Ali, 2015), largely influence the adoption of an innovation, our study demonstrates that BT is compatible with the sector's needs and values. However, there is a need to better articulate its relative advantage between the actors involved in its development. In addition, we believe that even-though Blockchain is perceived as relatively complex, this could be overcome through effective communication channels and governance systems.

The OECD encourages donors to "Work toward more shared analysis and pooled funding among donors, in order to strengthen coherence and co-ordination" (OECD, 2014, p. 68). Based on our research, we propose that the development aid sector could benefit from finding a common BT platform and framework to reinforce the collaboration between different parties and to move toward common norms around this technology. Instituting such governance arenas can expedite debates about security and the usability of the system for the beneficiaries, as well as the implications of this for the design of Blockchain platforms. Collaboration is central in setting the international standards and regulations to ensure the integrity of data, security and privacy and to minimize the potential downsides of this new technology.

Co-ordination is also a key in creating a knowledge sharing system between different parties with clear understanding of costs and benefits involved which, based on our study, we believe would benefit all parties and help foster the advances in the development of Blockchain Technology. Emerging initiatives, such as the EU Blockchain Observatory \& Forum, could help in answering technical questions and facilitate its adoption. In line with many reports and with previous research, we stress the importance of donor governments role in fostering the

\section{REFERENCES}

Abdolrahimi, C., Barsky, S., Brett, J., de Vaulx, F., Duong, D., Engel, B., et al. (2017). Enabling Blockchain Innovation in the U.S. Federal Government. American Council for Technology-Industry Advisory Council (ACT-IAC).

Bajpai, P. (2018). Microsoft And The Blockchain: MSFT's Big Projects. NASDAQ.Com. Available online at: https://www.nasdaq.com/article/ microsoft-and-the-blockchain-msfts-big-projects- $\mathrm{cm} 906244 \quad$ (accessed January 17, 2018).

Bauhr, M., and Grimes, M. (2014). Indignation or resignation: the implications of transparency for societal accountability: indignation or resignation. Governance 27, 291-320. doi: 10.1111/gove.12033

Berryhill, J., Bourgery, T., and Hanson, A. (2018). "Blockchains unchained: blockchain technology and its use in the public sector," in $O E C D$ Working Papers on Public Governance (Paris: OECD Publishing). doi: $10.1787 / 3$ c32c429-en

Blockchain Team (2018). The Future is Decentralised. The United Nations Development Programme.

BMZ (2016). Toolkit-Digitalisation in Development Cooperation and International Cooperation in Education, Culture and Media. Issuer: Federal Ministry for Economic Cooperation and Development (BMZ), Division Education and the Digital World. Available online at: https://www.bmz. development of BT and bringing different actors together. In addition, for BT to bring out meaningful change in aid flow accountability, debates around its development and use should better integrate the voice of the target populations.

We believe that collaboration is the key to overcome not only the risk averseness in this space but also to surmount technical obstacles such as developing standards to ensure security with authentication systems, interoperability with new and old systems and designing systems that can be scaled and upgraded with minimum cost/overhead.

Our study is only the first step in understanding different key actors' perceptions toward BT in development aid sector. We are hopeful that the results of this study could serve as important debate points about the potential role of BT in development. However, nuancing and additional substantiation of our claims would necessitate a more extensive empirical investigation.

\section{DATA AVAILABILITY STATEMENT}

All datasets generated for this study are included in the manuscript/supplementary files.

\section{AUTHOR CONTRIBUTIONS}

$\mathrm{AR}$ and $\mathrm{AM}$ contributed to the design of the research. AR performed the research. AM supervised the findings of AR's work. All authors discussed the results and contributed to the final manuscript.

\section{ACKNOWLEDGMENTS}

We would like to thank start-ups Alice, Disberse, and Curado for sharing their precious time. In addition, we are very grateful for the participation and input of all interviewees, each of whom brought a different light to this study.

de/en/zentrales_downloadarchiv/ikt/Toolkit-Digitalisation-DevelopmentEducation-Culture-Media.pdf (accessed April 04, 2019).

Botsman, R. (2017). How the Blockchain is Redefining Trust. Available online at: https://www.wired.com/story/how-the-blockchain-is-redefiningtrust/ (accessed December 27, 2017).

Breen, O.B. (2013). The disclosure panacea: a comparative perspective on charity financial reporting. VOLUNTAS Int. J. Volunt. Nonprofit Organ. 24, 852-80. doi: $10.1007 /$ s11266-013-9377-2

Burg, J., Murphy, C., and Pétraud, J.P. (2018). Blockchain for International Development: Using a Learning Agenda to Address Knowledge Gaps. Available online at: http://merltech.org/blockchain-for-international-developmentusing-a-learning-agenda-to-address-knowledge-gaps/ (accessed November 29, 2018).

Cook, R. (2018). Rohingya Crisis Highlights Blockchain Data Issues. Available online at: http://www.atimes.com/article/rohingya-crisis-highlights-blockchaindata-issues/ (accessed April 13, 2018).

Coppi, G., and Fast, L. (2019). Blockchain and Distributed Ledger Technologies in the Humanitarian Sector. Overseas Development Institute. Available online at: https://www.econstor.eu/handle/10419/193658 (accessed September 07, 2019).

Corporate Tracker (2018). Outlier Ventures. Available online at: https://outlierventures.io/corporate-tracker/ (accessed February 20, 2018). 
Cucciniello, M., Porumbescu, G.A., and Grimmelikhuijsen, S. (2017). 25 years of transparency research: evidence and future directions. Public Administ. Rev. 77, 32-44. doi: 10.1111/puar.12685

Davies, R. (2015). Giving Unchained: Philanthropy and the Blockchain. 4. Charities Aid Foundation. Available online at: https://www.cafonline.org/docs/ default-source/about-us-publications/givingunchained-philanthropy-andthe-blockchain.pdf (accessed March 29, 2018).

Dowlat, S. (2018). Cryptoasset Market Update. Available online at: https://medium. com/satis-group/cryptoasset-market-update-b678aeda4c5e (accessed March 29, 2018).

Etzioni, A. (2010). Is transparency the best disinfectant? J. Polit. Philos. 18, 389-404. doi: 10.1111/j.1467-9760.2010.00366.x

Fabian, C. (2018). Un-chained: experiments and learnings in crypto at UNICEF. Innov. Technol. Govern. Global. 12, 30-45. doi: 10.1162/inov_a_00265

Galen, D., Brand, N., Boucherle, L., Davis, R., Do, N., El-Baz, B., et al. (2017). Blockchain for Social Impact: Moving beyond the Hype. Stanford Graduate School of Business Center for Social Innovation and Ripple Works.

Global Tolerance (2015). The Values Revolution. Global Tolerance. Available online at: http://crnavigator.com/materialy/bazadok/405.pdf (accessed April 18, 2018).

Grand Bargain (2016). The Grand Bargain-A Shared Commitment to Bettre Serve Pople in Need. Istanbul: Grand Bargain.

Grimmelikhuijsen, S. (2011). Being transparent or spinning the message? An experiment into the effects of varying message content on trust in government. Info. Pol. 16, 35-50. doi: 10.3233/IP-2011-0222

GSMA (2017). Blockchain for Development: Emerging Opportunities for Mobile, Identity and Aid. London: GSMA. Available online at: https://www.gsma. com/mobilefordevelopment/wp-content/uploads/2017/12/Blockchain-forDevelopment.pdf (accessed March 29, 2018).

Haan, C. (2018). USAID: All 43 Blockchain Charity Projects Studied Unwilling to Prove Claims. Available online at: https://www.crowdfundinsider.com/2018/ 12/141938-usaid-all-43-blockchain-charity-projects-studied-unwilling-toprove-claims/ (accessed December 3, 2018).

Hernandez, K. (2017). Blockchain for development-hope or hype? Inst. Dev. Stud. Rapid Resp. Brief. 17, 1-4.

High-Level Panel on Humanitarian Financing (2016). Too Important to FailAddressing the Humanitarian Financing Gap. (Report to the Secretary-General). New York: United Nations: High-Level Panel on Humanitarian Financing Report to the United Nations Secretary-General.

Hood, C. (2007). What happens when transparency meets blame-avoidance? Publ. Manag. Rev. 9, 191-210. doi: 10.1080/14719030701340275

IASC (2013). Accountability to Affected Populations-IASC Commitments. IASC Taskforce on Accountability to Affected Populations. Available online at: https://interagencystandingcommittee.org/system/files/legacy_files/IASC \%20Principals\%20commitments\%20on\%20AAP\%20\%28CAAP\%29March \%202013.pdf (accessed May 30, 2019).

IATI (2016). Annual Report. Available online at: https://www.aidtransparency.net/ wp-content/uploads/2017/03/IATI-Annual-Report-2016-EN.pdf (accessed April 31, 2018).

Juskalian, R. (2018). Inside the Jordan Refugee Camp That Runs on Blockchain. MIT Technology Review. Available online at: https://www.technologyreview.com/s/ 610806/inside-the-jordan-refugee-camp-that-runs-on-blockchain/ (accessed April 30, 2018).

Kaminski, J. (2011). Diffusion of Innovation Theory. Can J. Nurs. Inform. 6. Theory in Nursing Informatics Column. Available online at: http://cjni.net/journal/?p= 1444 (accessed June 22, 2019).

Kemper, N., and Sattelberger, Dr. J. (2017). Blockchain Technology: How it Works and What Potential it Offers for Development. KfW Development Research.

Ko, V., and Verity, A. (2016). BlockChain for the Humanitarian Sector-Future Opportunities. Digital Humanitarian Network, UN-OCHA.

Kohlhaas, P. (2017). An Introduction to Polkadot and Parachains. Keeping Stock. Available online at: https://keepingstock.net/a-dummiesguide-to-polkadot-and-parachains-93708bd90775 (accessed February 7, 2017).

Lannquist, A. (2018). Blockchain in Enterprise: How Companies are Using Blockchain Today. Blockchain at Berkeley. Available online at: https:// blockchainatberkeley.blog/a-snapshot-of-blockchain-in-enterprised140a511e5fd (accessed January 19, 2018).
Lyons, T., Courcelas, L., and Timsit, K. (2018a). Blockchain and the GDPR. European Union Blockchain Observatory and Forum. Available online at: https://www.eublockchainforum.eu/sites/default/files/reports/20181016_ report_gdpr.pdf?width=1024\&height=800\&iframe=true (accessed October 16, 2018).

Lyons, T., Courcelas, L., and Timsit, K.. (2018b). Blockchain for Government and Public Services. The European Union Blockchain Observatory and Forum.

Marr, B. (2018). Blockchain is Changing Our World: Here are the Best Practical Examples of how it is Used in 2018. Available online at: https://www.forbes. com/sites/bernardmarr/2018/01/10/blockchain-is-changing- our-world-hereare-the-best-practical-examples-of-how-it-is-used-in-2018/ (accessed May $11,2018)$.

McGee, R. (2013). Aid transparency and accountability: 'build it and they'll come'? Dev. Pol. Rev. 31, S107-S124. doi: 10.1111/dpr.12022

Melendéz, S. E. (2001). The nonprofit sector and accountability: the nonprofit sector and accountability. New Direct. Philanthropic Fundraising 2001, 121-32. doi: $10.1002 /$ pf.3107

Metcalfe-Hough, V., Poole, L., Bailey, S., and Belanger J. (2018). Grand Bargain Annual Independent Report. London: Humanitarian Policy Group. Available online at: https://www.agendaforhumanity.org/sites/default/files/resources/ 2018/Jun/Grand\%20Bargain\%20annual\%20independent\%20report\%202018_ execsumm.pdf (accessed May 30, 2019).

Natarajan, H., Krause, S., and Gradstein, H. (2017). Distributed Ledger Technology (DLT) and Blockchain. FinTech Note 1. Washington, DC: World Bank Group. Available online at: https://openknowledge.worldbank.org/bitstream/handle/ 10986/29053/WP-PUBLIC-Distributed-Ledger-Technology-and-BlockchainFintech-Notes.pdf?sequence=18isAllowed $=y$ (accessed April 04, 2019).

Nelson, P. (2018). Primer on Blockchain: How to Assess the Relevance of Distributed Ledger Technology to International Development. United States Agency for International Development (USAID).

Nomura Research Institute (2016). Survey on Blockchain Technologies and Related Services. Japan's Ministry of Economy, Trade and Industry (METI). Available online at: https://www.meti.go.jp/english/press/2016/pdf/0531_01f. pdf (accessed April 04, 2019).

OECD (2005). Managing Aid: Practices of DAC Member Countries. DAC Guidelines and Reference Series. Paris: OECD Publishing.

OECD (2006). Harmonising Donor Practices for Effective Aid Delivery, Vol. 2: Budget Support, Sector Wide Approaches and Capacity Development in Public Financial Management. DAC Guidelines and Reference Series. Paris: OECD Publishing.

OECD (2014). Accountability and Democratic Governance: Orientations and Principles for Development. DAC Guidelines and Reference Series. Paris: OECD Publishing.

OECD (2019). Total Official and Private Flows (Indicator). Available online at: https://doi.org/10.1787/52c1b6b4-en (accessed September 02, 2019).

OECD and DAC (2019). Ranking of the Largest Development Aid Donors in 2017 (in Million U.S. Dollars). Available online at: https://www-statista-com. ezproxy.hec.fr/statistics/263287/ranking-742 of-the-largest-developmentaid-donors/ (accessed March 04, 2019).

Ølnes, S., Ubacht, J., and Janssen, M. (2017). Blockchain in government: benefits and implications of distributed ledger technology for information sharing. Govern. Info. Q. 34, 355-64. doi: 10.1016/j.giq.2017. 09.007

Orcutt, M. (2018). The World Bank Is a Verified Blockchain Booster. MIT Technology Review. Available online at: https://www.technologyreview. com/s/612043/the-world-bank-is-a-verified-blockchain-booster/ (accessed September 13, 2018).

Pisa, M., and Juden, M. (2017). "Blockchain and economic development: hype vs. reality," in CGD Policy Paper. Washington, DC: Center for Global Development. Available online at: https://www.cgdev.org/publication/ blockchain-and-economic-development-hype-vs-reality (accessed January 23, 2018).

Publish What You Fund (2010). Briefing Paper 1: Why Aid Transparency Matters, and the Global Movement for Aid Transparency. London: Publish What You Fund. Available online at: http://www.publishwhatyoufund.org/files/BP1_final. pdf (accessed March 31, 2018). 
Rogers, E.M. (1962). Diffusion of Innovations. 1st Edn. New York, NY: Free Press. Rugeviciute, A. (2018). From vision to reality: transparency and accountability in aid development using blockchain technology (MSc thesis). HEC Paris, Paris, France.

Scott, W. R. (2001). Institutions and Organizations. New York, NY: Sage Publications Ltd.

Smith, R. T. (2017). Public and Private Blockchains: Enemies or Allies? Available online at: https://medium.com/@rtylersmith/public-andprivate-blockchains-enemies-or-allies-45f050c38fc0 (accessed February $28,2017)$.

Swan, M. (2015). Blockchain: Blueprint for a New Economy. 1st Edn. Beijing Cambridge Farnham Köln Sebastopol Tokyo: O'Reilly.

Terzo, G. (2018). Pineapple Fund's \$5 Million Bitcoin Donation Boosts Medicine Foundation. CCN. Available online at: https://www.ccn.com/pineapple-funds5-mil-bitcoin-donation-boosts-medicine-foundation (accessed February 3, 2018).

The Economist (2015). The Trust Machine. Available online at: https://www. economist.com/news/leaders/21677198-technology-behind-bitcoin-couldtransform-how-economy-works-trust-machine (accessed October 31, 2015).

Toledano, J., and Janin, L. (2018). Les Enjeux des Blockchains. Paris: France Stratégie.

Walport, M. (2016). Distributed Ledger Technology: Beyond Block Chain. London: UK Government Office for Science.
Wani, T. A., and Ali, S. W. (2015). Innovation diffusion theory review and scope in the study of adoption of smartphones in India. J. General Manag. Res. $3,101-118$.

Weizsäcker, F., and Eggler, S. (2018). GIZ Blockchain Lab. Berlin. Available online at: https://www.giz.de/en/downloads/Factsheet_Blockchain\%20Lab.pdf (accessed February 24, 2019).

Zambrano, R. (2017). Blockchain: Unpacking the Disruptive Potential of Blockchain Technology for Human Development. Ottawa, ON: International Development Research Centre. Available online at: https://idl-bnc-idrc.dspacedirect.org/ bitstream/handle/10625/56662/IDL-56662.pdf?sequence $=2$ \&isAllowed $=y$

Zwitter, A., and Boisse-Despiaux, M. (2018). Blockchain for humanitarian action and development aid. J. Int. Hum. Act. 3:16. doi: 10.1186/s41018-018-0044-5

Conflict of Interest: The authors declare that the research was conducted in the absence of any commercial or financial relationships that could be construed as a potential conflict of interest.

Copyright (c) 2019 Rugeviciute and Mehrpouya. This is an open-access article distributed under the terms of the Creative Commons Attribution License (CC BY). The use, distribution or reproduction in other forums is permitted, provided the original author(s) and the copyright owner(s) are credited and that the original publication in this journal is cited, in accordance with accepted academic practice. No use, distribution or reproduction is permitted which does not comply with these terms. 